\title{
Experimental study on the efficiency and safety of the manual hyperinflation maneuver as a secretion clearance technique ${ }^{* * * *}$
}

\author{
Estudo experimental sobre a eficiência e segurança da manobra de \\ hiperinsuflação manual como técnica de remoção de secreção
}

\author{
Tatiana de Arruda Ortiz, Germano Forti, Márcia Souza Volpe, \\ Carlos Roberto Ribeiro Carvalho, Marcelo Brito Passos Amato, Mauro Roberto Tucci
}

\begin{abstract}
Objective: To evaluate, in a lung model simulating a mechanically ventilated patient, the efficiency and safety of the manual hyperinflation $(\mathrm{MH})$ maneuver as a means of removing pulmonary secretions. Methods: Eight respiratory therapists (RTs) were asked to use a self-inflating manual resuscitator on a lung model to perform $\mathrm{MH}$ as if to remove secretions, under two conditions: as routinely applied during their clinical practice; and after receiving verbal instructions based on expert recommendations. In both conditions, three clinical scenarios were simulated: normal lung function, restrictive lung disease, and obstructive lung disease. Results: Before instruction, it was common for an RT to compress the resuscitator bag two times, in rapid succession. Proximal pressure $\left(\mathrm{P}_{\text {prox }}\right)$ was higher before instruction than after. However, alveolar pressure $\left(\mathrm{P}_{\text {alv }}\right)$ never exceeded 42.5 $\mathrm{cmH}_{2} \mathrm{O}$ (median, 16.1; interquartile range [1QR], 11.7-24.5), despite $\mathrm{P}_{\text {prox }}$ values as high as $96.6 \mathrm{cmH}_{2} \mathrm{O}$ (median, 36.7; $1 \mathrm{QR}, 22.9-49.4)$. The tidal volume $\left(\mathrm{V}_{\mathrm{T}}\right)$ generated was relatively low (median, $\left.640 \mathrm{~mL} ; 1 \mathrm{R}, 505-735\right)$, and peak inspiratory flow (PIF) often exceeded peak expiratory flow (PEF), the median values being 1.37 L/s (1QR, 0.99-1.90) and $1.01 \mathrm{~L} / \mathrm{s}(1 \mathrm{QR}, 0.55-1.28)$, respectively. A PIF/PEF ratio < 0.9 (which theoretically favors mucus migration toward the central airways) was achieved in only $16.7 \%$ of the maneuvers. Conclusions: Under the conditions tested, $\mathrm{MH}$ produced safe $\mathrm{P}_{\text {alv }}$ levels despite high $\mathrm{P}_{\text {prox }}$. However, the $\mathrm{MH}$ maneuver was often performed in a way that did not favor secretion removal (PIF exceeding PEF), even after instruction. The unfavorable PIF/ PEF ratio was attributable to overly rapid inflations and low $\mathrm{V}_{\mathrm{T}}$.
\end{abstract}

Keywords: Physical therapy modalities; Respiratory therapy; Respiratory mechanics; Positive-pressure respiration.

\section{Resumo}

Objetivo: Avaliar, em um modelo pulmonar simulando um paciente sob ventilação mecânica, a eficiência e a segurança da manobra de hiperinsuflação manual (HM) com o intuito de remover secreção pulmonar. Métodos: Oito fisioterapeutas utilizaram um ressuscitador manual autoinflável para realizar HM com o objetivo de remover secreções, em duas condições: conforme rotineiramente aplicada durante sua prática clínica, e após receberem instruções verbais baseadas em recomendações de especialistas. Três cenários clínicos foram simulados: função pulmonar normal, doença pulmonar restritiva e doença pulmonar obstrutiva. Resultados: Antes da instrução, o uso de duas compressões sequenciais do ressuscitador era comum, e a pressão proximal $\left(\mathrm{P}_{\text {prox }}\right)$ foi mais alta em relação à obtida após a instrução. Entretanto, a pressão alveolar $\left(\mathrm{P}_{\text {lv }}\right)$ nunca excedeu $42,5 \mathrm{cmH}_{2} \mathrm{O}$ (mediana, 16,1 ; intervalo interquartil [1Q], 11,7-24,5), mesmo com valores de $\mathrm{P}_{\text {prox }}$ de até $96,6 \mathrm{cmH}_{2} 0$ (mediana, 36,7; 1Q, 22,9-49,4). 0 volume corrente (VC) gerado foi relativamente pequeno (mediana, $640 \mathrm{~mL}$; 1Q, 505-735) e o pico de fluxo inspiratório (PFl) geralmente excedeu o pico de fluxo expiratório (PFE): 1,37 L/s (1Q, 0,99-1,90) e 1,01 L/s (1Q, 0,55-1,28), respectivamente. Uma relação $\mathrm{PFl} / \mathrm{PFE}<0,9$ (que teoricamente favorece a migração do muco em direção às vias aéreas centrais) foi obtida em somente 16,7\% das manobras. Conclusões: Nas condições testadas, a $\mathrm{HM}$ gerou valores seguros de $\mathrm{P}_{\text {alv }}$ mesmo com altas $\mathrm{P}_{\text {prox }}$. Entretanto, a HM foi comumente realizada de um modo que não favorecia a remoção de secreção (PFl excedendo PFE) mesmo após a instrução. A relação $\mathrm{PFl} / \mathrm{PFE}$ desfavorável foi explicada pelas insuflações rápidas e o baixo VC.

Descritores: Modalidades de fisioterapia; Terapia respiratória; Mecânica respiratória; Respiração com pressão positiva.

\footnotetext{
* Study conducted in the Laboratório de Investigação Médica 09 (LIM-09, Laboratory for Medical Research 09), specializing in Pulmonology, University of São Paulo School of Medicine, São Paulo, Brazil.

Correspondence to: Mauro R. Tucci. Laboratório de Pneumologia LIM-09, Faculdade de Medicina da Universidade de São Paulo, Avenida Dr. Arnaldo, 455, $2^{\circ}$ andar, sala 2144, CEP 01246-903, São Paulo, SP, Brasil.

Tel. 5511 3061-7361. Fax: 5511 3061-2492.E-mail: mrotucci@gmail.com

Financial support: This study received financial support from the Fundação de Amparo à Pesquisa do Estado de São Paulo (FAPESP, São Paulo Research Foundation) and the Brazilian Financiadora de Estudos e Projetos (Finep, Financing Agency for Studies and Projects).

Submitted: 2 July 2012. Accepted, after review: 14 January 2013.

${ }^{*}$ A versão completa em português deste artigo está disponível em www.jornaldepneumologia.com.br
} 


\section{Introduction}

Manual hyperinflation $(\mathrm{MH})$ is a proposed technique that is purported to promote secretion clearance and to re-expand areas of atelectasis, thereby improving lung compliance and oxygenation in patients on mechanical ventilation. ${ }^{(1,2)}$ Despite a lack of scientific evidence confirming its benefits on clinical outcomes, ${ }^{(2-5)} \mathrm{MH}$ is often used in the ICU as a chest physiotherapy technique. The maneuver is widely accepted as effective $^{(6,7)}$ and, in Brazil, is largely embraced as a means of removing retained secretions. ${ }^{(8-10)}$ The rationale for the use of the technique as an aid for secretion removal is that it simulates a cough. ${ }^{(11)}$ When applied before suctioning, it theoretically moves secretions toward the central airways, ${ }^{(12)}$ thus increasing the efficacy of the suctioning procedure.

There has been considerable debate regarding the safety and efficiency of MH..$^{(1,3)}$ It has been shown that the efficiency of the MH maneuver is affected by the operator and the type of manual resuscitator used, ${ }^{(13,14)}$ as well as by the resistance and compliance of the respiratory system, ${ }^{(15,16)}$ largely affecting the pressures and flows generated in the respiratory system. Under certain conditions, the use of this technique can generate high peak airway pressures, increasing the risk of barotrauma. ${ }^{(17)}$

According to expert recommendations, ${ }^{(1,11,18)}$ in order to promote secretion clearance, $\mathrm{MH}$ should consist of a slow, deep inspiration, an inspiratory pause, and a quick release of the resuscitation bag to promote passive exhalation with high expiratory flow rates. However, the way in which the $\mathrm{MH}$ maneuver is performed can vary from country to country, impeding the understanding of its effects. . $^{(1,3,5)}$

Since the 1980s, there has been increasing evidence that the peak expiratory flow to peak inspiratory flow (PEF/PIF) ratio is a critical factor for the removal of lung secretions, especially in heavily sedated or paralyzed patients..$^{(19-21)} \mathrm{In}$ fact, more than their ratio, the difference between the two, in terms of their absolute values, seems to be the major determinant: above a given threshold, whenever the PIF exceeds the PEF, secretions migrate deeper into the lung. ${ }^{(21)}$

Intuitively, respiratory therapists (RTs) have been promoting maneuvers to increase expiratory flows, analogous to those observed during coughing. However, relatively little attention has been given to their inspiratory counterpart, despite expert recommendations to apply a slow, deep inspiration during $\mathrm{MH}$. The inspiratory phase of MH can be performed in many different ways, depending on the personal experience of the operator, and there is little evidence that the $\mathrm{MH}$ maneuver generates an adequate flow bias (i.e., with PEF exceeding PIF) or that the ultimate goal of the maneuver (i.e., improved secretion clearance) is achieved.

The aim of this study was to evaluate the efficiency and safety of MH (as performed by RTs in a lung model simulating a mechanically ventilated patient) as a means of increasing secretion clearance under two different conditions: $\mathrm{MH}$ performed in accordance with the routine clinical practice of RTs; and MH performed in accordance with expert recommendations. ${ }^{(1,15,18)}$ The efficiency of MH was determined through analysis of the volume and flow patterns generated in relation to the anticipated effects on secretion removal. The safety of $\mathrm{MH}$ was evaluated on the basis of the inspiratory pressures achieved (i.e., whether those pressures remained within safe limits during the maneuver). Our ultimate objective was to obtain a qualitative analysis of how $\mathrm{MH}$ is performed by experienced professionals and not to address how it is performed in Brazil.

\section{Methods}

This was an experimental study conducted in the Laboratory for Medical Research 09, specializing in Pulmonology, at the University of São Paulo School of Medicine, in the city of São Paulo, Brazil. The study was approved by the Research Ethics Committee of the University of São Paulo School of Medicine Hospital das Clínicas. All participants gave written informed consent.

The study comprised two phases, evaluating the effects of MH, as performed by RTs, in promoting the clearance of pulmonary secretions. In the first phase (the pre-instruction phase), the RTs were given no explicit verbal instructions on how to apply the maneuver. In the second phase, the RTs were given instructions based on expert recommendations, as detailed below. The two phases are hereafter referred to as the pre- and post-instruction phases.

All maneuvers were performed with selfinflating manual resuscitator (SPUR ${ }^{\circledast}$; Ambu, Ballerup, Denmark), with a capacity of $1,500 \mathrm{~mL}$. 
The maneuver was applied by eight experienced RTs (four males and four females), with an average of 2.6 years in practice (range, 2-4 years) in ICUs in the city of São Paulo. Five of the eight had graduated from universities located within the state of São Paulo, and all had completed one of the one-year postgraduate training programs in respiratory therapy offered by university hospitals.

The maneuver was applied to a mechanical model of the respiratory system known as a training and test lung (TTL 2600; Michigan Instruments, Grand Rapids, M1), connected to a tracheal tube $(8.5 \mathrm{~mm})$. The airway flow was measured proximally (between the manual resuscitator and proximal pressure sensor) by a pneumotach. Two pressure transducers were connected to the model: one to measure proximal pressure $\left(\mathrm{P}_{\text {prox }}-\right.$ at the airway, between the flow sensor and tracheal tube); and another to record alveolar pressure $\left(\mathrm{P}_{\text {alv }}\right)$. Figure 1 illustrates the experimental setup.

In both study phases, we altered the resistance and compliance of the lung model in order to simulate three different clinical scenarios: a patient with obstructive lung disease (resistance at $20 \mathrm{cmH}_{2} \mathrm{O} / \mathrm{L}$ per second and compliance at $0.08 \mathrm{~L} / \mathrm{cmH}_{2} \mathrm{O}$ ); a normal patient (resistance at $5 \mathrm{cmH}_{2} \mathrm{O} / \mathrm{L}$ per second and compliance at 0.05 $\mathrm{L} / \mathrm{cmH}_{2} \mathrm{O}$ ); and a patient with restrictive lung disease (resistance at $5 \mathrm{cmH}_{2} \mathrm{O} / \mathrm{L}$ per second and compliance at $0.025 \mathrm{~L} / \mathrm{cmH}_{2} 0$ ).

In the pre-instruction phase (as previously mentioned), the RTs were instructed to perform $\mathrm{MH}$ to promote pulmonary secretion clearance in accordance with their routine clinical practice. The lung model was set according to those three clinical scenarios explained above and covered with a bed sheet, allowing RTs to sense the movement of the bellows while remaining blinded to the clinical scenario selected. After approximately eight cycles of $\mathrm{MH}$, the settings were changed to simulate the next scenario (in the sequence described above) until all three scenarios had been run. In the post-instruction phase, each RT received brief verbal instructions on how to perform $\mathrm{MH}$ according to expert recommendations, ${ }^{(1,11,18)}$ and all of the steps performed in the pre-instruction phase were repeated. The verbal instructions were given within the space of approximately $2 \mathrm{~min}$, and the RTs were not trained to follow a given pattern of insufflation. The instructions were always given by the same researcher, who instructed each RT as follows: "Now you should perform MH with a slow inflation and a 2-s inspiratory pause, followed by rapid release of the bag". While giving the instructions, the researcher demonstrated the maneuver with the manual resuscitator used in the study. The instructions were given twice.

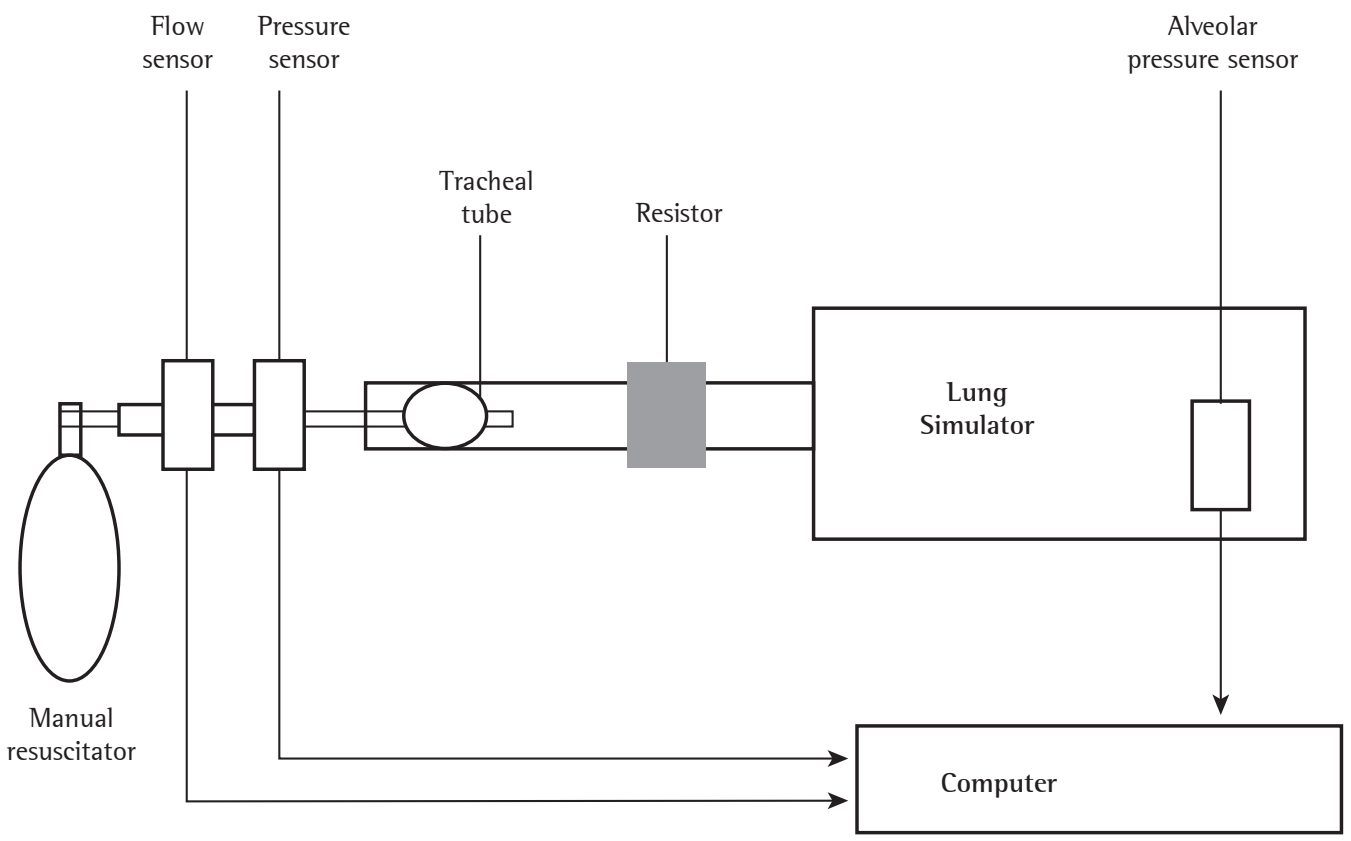

Figure 1 - Experimental setup. 
The analog signals from the flow and pressure transducers were amplified, digitized, and recorded at $200 \mathrm{~Hz}$, using a data acquisition and off-line analysis system developed within the software Laboratory Virtual Instrumentation and Engineering Workbench (LabVIEW; National Instruments, Austin, TX, USA). For each experimental condition, three of the (approximately) eight respiratory cycles were randomly selected for analysis. The beginning of the inspiratory phase was defined as zero flow immediately before bagging, and the end of the respiratory cycle was defined as zero flow at the end of exhalation. The $\mathrm{P}_{\text {prox }}$ was defined as the peak pressure value during the inspiratory phase, measured by the proximal pressure transducer. The PIF was defined as the peak flow value during the inspiratory phase, measured by the flow transducer, and the PEF was defined as the peak flow during expiratory phase. Tidal volume $\left(\mathrm{V}_{\mathrm{T}}\right)$ was calculated by integration of the inspiratory flow signal. The $\mathrm{P}_{\text {alv }}$ was defined as the peak pressure value during the inspiratory phase, measured by the alveolar pressure transducer. Inspiratory time $\left(\mathrm{T}_{1}\right)$ was defined as the duration of the inflation plus the inspiratory pause.

Data are shown as median and 25-75\% interquartile range (IQR). Repeated measures ANOVA was used to evaluate, for each variable, the following within-subject factors: the three clinical scenarios; and the two phases (before and after instructions). All two-way interactions between those factors were also tested. Inspiratory versus expiratory flow and alveolar versus proximal pressures were also tested as within-subject factors to compare peak flow and peak pressure variables, respectively. Values of $p<0.05$ were considered statistically significant.

\section{Results}

For each of the six experimental conditions (three clinical scenarios in each study phase), we analyzed three respiratory cycles, corresponding to eighteen respiratory cycles for each of the eight RTs. Therefore, we analyzed a total of 144 respiratory cycles.

Among all of the respiratory cycles analyzed, the maximum $\mathrm{P}_{\text {alv }}$ observed was $42.5 \mathrm{cmH}_{2} \mathrm{O}$ (median, $16.1 \mathrm{cmH}_{2} 0$; 1QR, 11.7-24.5), despite the much higher $\mathrm{P}_{\text {prox }}$ values (maximum, 96.6 $\mathrm{CmH}_{2} \mathrm{O}$-median, 36.7; 1QR, 22.9-49.4). The $\mathrm{V}_{\mathrm{T}}$ values were relatively low (maximum, $955 \mathrm{~mL}-$ median, 640; 1QR, 505-735), and the $\mathrm{T}_{1}$ was short (median, $1.29 \mathrm{~s} ; 1 \mathrm{1QR}, 0.95-1.72$ ).

Overall, PIF was significantly higher than PEF $(p<0.02)$. A PIF/PEF ratio < 0.9, which theoretically favors mucus migration toward the central airways, ${ }^{(19)}$ was achieved in only 24 (16.7\%) of the 144 maneuvers evaluated. This favorable ratio occurred primarily in the postinstruction phase (in 18 of the 24 maneuvers) and was strongly associated with just one of the RTs tested (who was responsible for 12 of the 24 maneuvers). During the pre-instruction phase, six of the eight RTs performed $\mathrm{MH}$ using two compressions of the resuscitator bag and produced a PIF higher than that produced in the post-instruction phase (Figure 2).

Table 1 shows a comparison between the pre- and post-instruction phases, in terms of the mechanical variables evaluated. After instruction, $\mathrm{MH}$ was performed in a slower manner, with a
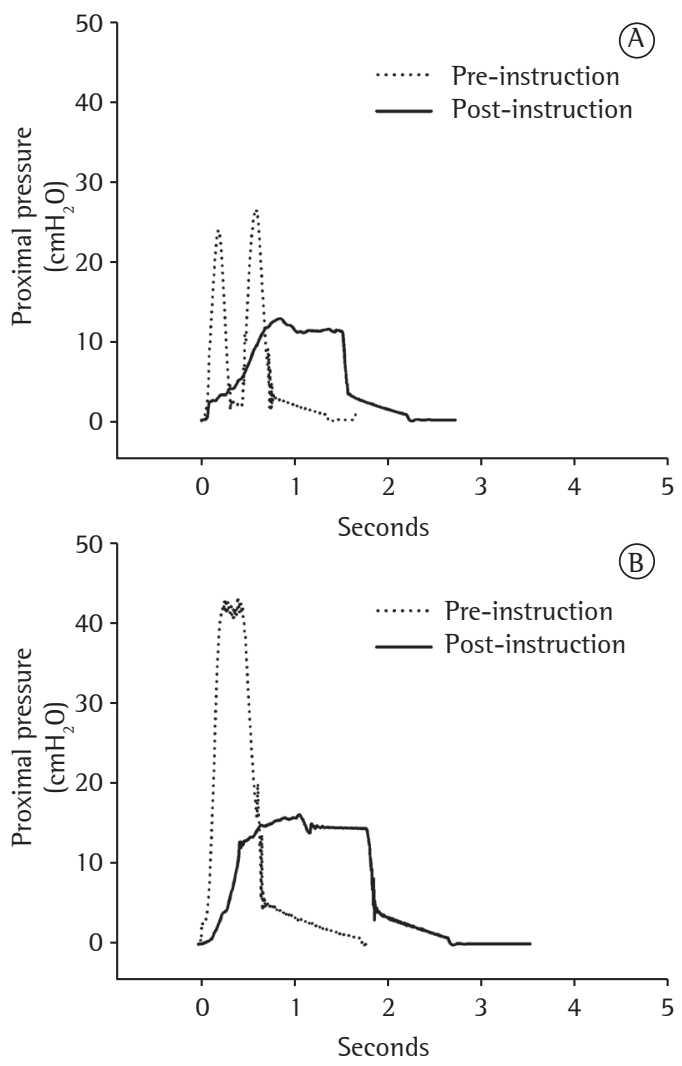

Figure 2 - Differences in proximal pressures achieved by two different respiratory therapists ( $A$ and $B$ ) before and after explicit verbal instruction (routine clinical practice vs. expert recommendations-dashed lines and solid lines, respectively). 
Table 1 - Mechanical variables before and after verbal instruction (routine clinical practice vs. expert recommendations).

\begin{tabular}{lccc}
\hline \multicolumn{1}{c}{ Variable } & Pre-instruction & Post-instruction & $\mathrm{p}$ \\
\hline Proximal pressure $\left(\mathrm{cmH}_{2} \mathrm{O}\right)$ & $44.5(33.4-63.4)$ & $26.8(18.6-37.5)$ & 0.004 \\
Alveolar pressure $\left(\mathrm{cmH}_{2} \mathrm{O}\right)$ & $16.3(11.6-25.8)$ & $14.8(11.7-23.8)$ & 0.93 \\
Peak inspiratory flow $(\mathrm{L} / \mathrm{s})$ & $1.84(1.28-2.19)$ & $1.14(0.87-1.44)$ & 0.001 \\
Peak expiratory flow $(\mathrm{L} / \mathrm{s})$ & $1.04(0.57-1.33)$ & $0.99(0.55-1.27)$ & 0.28 \\
Tidal volume $(\mathrm{mL})$ & $628(497-699)$ & $647(518-746)$ & 0.63 \\
Inspiratory time $(\mathrm{s})$ & $0.95(0.78-1.19)$ & $1.71(1.44-2.13)$ & $<0.001$ \\
PIF/PEF ratio & $1.80(1.29-2.34)$ & $1.15(0.87-1.80)$ & 0.004 \\
\hline
\end{tabular}

Values are expressed as median (25-75\% interquartile range). PIF: peak inspiratory flow; PEF: peak expiratory flow.

longer $\mathrm{T}_{1}$ and a lower PIF, producing a lower $\mathrm{P}_{\text {prox }}$. There were no statistically significant differences between the two phases in terms of the $\mathrm{P}_{\text {alv }}$, $V_{T}$ and PEF. Figure 2 illustrates the difference between the two study phases and between two different RTs.

Comparing all three clinical scenarios tested and the two phases of the study, we found that $P_{\text {prox }}$ was markedly higher than was $P_{\text {alv }}$ in all instances, with the exception of the restrictive lung disease scenario in the post-instruction phase (Figure 3). In the pre-instruction phase, $\mathrm{PIF}$ values were consistently higher than were PEF values. In the post-instruction phase, the PIF/ PEF ratio was closer to $1: 1$. The only situation in which that ratio was consistently unfavorable (PIF still far exceeding PEF) was the obstructive lung disease scenario (Figure 4).

\section{Discussion}

The major finding of the present study was that, even after receiving explicit instructions, the RTs evaluated here performed $\mathrm{MH}$ in a way that probably would not aid secretion removal, with PIF commonly exceeding PEF. Compressing the resuscitator bag multiple times, in rapid succession, resulted in high values of PIF and $P_{\text {prox }}$. However, this finding was typically associated with a relatively low $V_{T}$, probably because of short bag-compression times. Therefore, the $\mathrm{P}_{\text {alv }}$ was often low at the start of exhalation, resulting in a low PEF. Both factors (rapid, multiple compressions and low $\mathrm{P}_{\mathrm{alv}}$ ) appear to be responsible for the unfavorable relationship between PIF and PEF. Finally, although the MH maneuver might not promote secretion clearance, our results suggest that this maneuver, as performed in our study, is unlikely to cause barotrauma, a concern expressed by other authors because of the high
$P_{\text {prox }}$ it generates. ${ }^{(17)}$ In the present study, we also observed high $\mathrm{P}_{\text {prox }}$ values. However, the $\mathrm{P}_{\text {alv }}$ values-roughly represented by plateau pressures, which correlate better with barotrauma than do $P_{\text {prox }}$ values-were within the safe range.

The MH maneuver was originally described as consisting of a slow, deep inspiration, with an inspiratory pause and rapid release of the resuscitator bag. ${ }^{(22)}$ Since then, many different $\mathrm{MH}$ techniques have been described, including one providing a $\mathrm{V}_{\mathrm{T}}$ that is greater than the baseline $V_{T}$ for the patient in question ${ }^{(15)}$; one providing a $V_{T}$ that is $50 \%$ greater than that delivered by the ventilator ${ }^{(23)}$; and one consisting of a slow (3-s) inspiration to achieve a peak airway pressure of $40 \mathrm{cmH}_{2} \mathrm{O}^{(24)}$ In contrast, we found that RTs working in the city of São Paulo have customized the maneuver according to personal practice and bias, frequently applying two compressions of the resuscitator bag, without an inspiratory pause, resulting in PIF being higher than PEF. One possible explanation is that the maneuver applied in that way stimulates coughing and, consequently, improves secretion clearance, or at least gives the RT that impression. As observed in this study, however, applying the maneuver in that way might make it ineffective, with unfavorable relationships between inspiratory and expiratory flows, especially if the patient has a depressed cough reflex or is unable to cough efficiently.

According to previous studies, ${ }^{(19,20)}$ above a given flow threshold, the direction of mucus transport (in or out of the respiratory system) is governed by the highest peak flow: a PEF 10\% higher than the PIF (i.e., a PIF/PEF ratio < 0.9) will favor secretion movement from the distal to the central airways. A recent study evaluating the transport of artificial mucus in a test lung system $^{(21)}$ reported that mucus transport is better explained by the absolute difference between PIF 


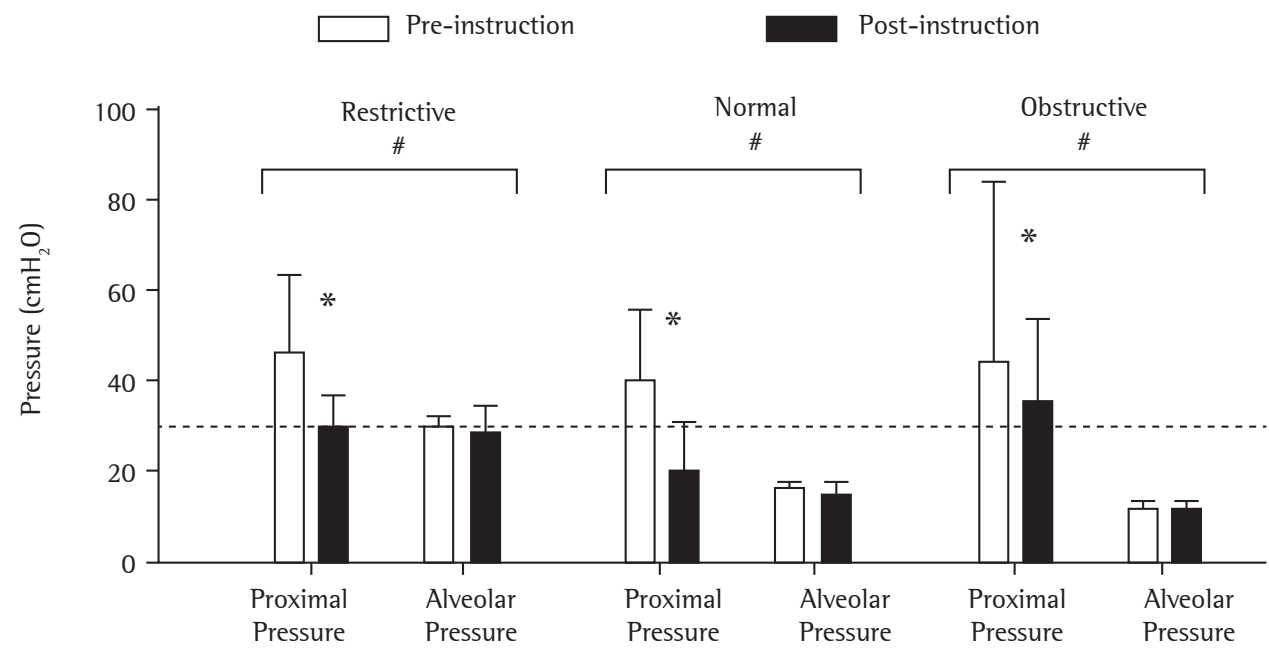

Figure 3 - Median values of proximal and alveolar pressures (interquartile ranges as error bars) obtained in the pre-instruction (routine clinical practice) and post-instruction (in accordance with expert recommendations) phases of the study. The major effect of instruction was the generation of lower proximal pressures. The dashed line indicates $30 \mathrm{cmH}_{2} 0$. ${ }^{*} \mathrm{p}<0.01$ (difference between pre-instruction and post-instruction). \#p $<0.05$ (difference between proximal and alveolar pressure).

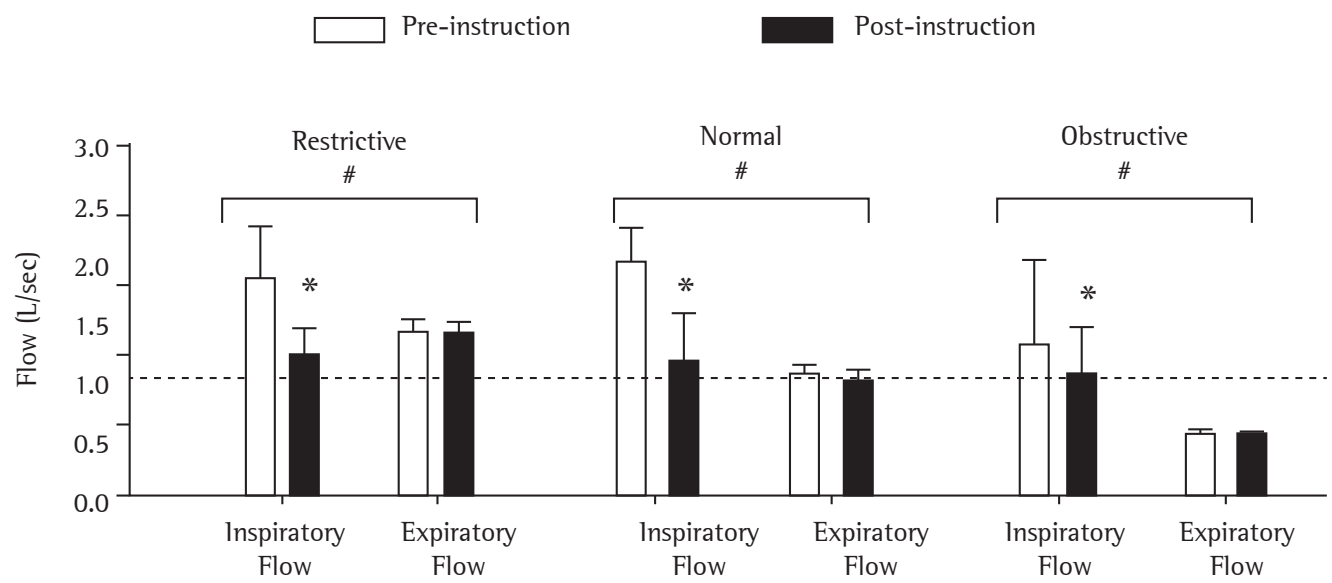

Figure 4 - Median values for peak inspiratory and expiratory flows (interquartile ranges as error bars) obtained in the pre-instruction (routine clinical practice) and post-instruction (in accordance with expert recommendations) phases of the study. The major effect of instruction was the generation of lower peak inspiratory flow. The dashed line indicates $1 \mathrm{~L} / \mathrm{sec} .{ }^{*} \mathrm{p}<0.01$ (difference between pre-instruction and postinstruction). ${ }^{*} p<0.05$ (difference between peak inspiratory and expiratory flows).

and PEF than by the PIF/PEF ratio. When PEF is higher than PIF, a greater difference between the two translates to better mucus transport. In the present study, the PIF/PEF ratio was below 0.9 in only $24(16.7 \%)$ of the 144 maneuvers evaluated, most of those 24 being performed in the post-instruction phase. Consequently, the median PIF was much higher than was the median PEF, which is a cause for great concern. This disappointing result is in agreement with the findings of some other studies in which self-inflating resuscitators were also used. ${ }^{(5,25)}$

The manual resuscitator tested in the present study had a self-inflating bag (the type of manual resuscitator most widely used in ICUs in Brazil). Such resuscitators usually generate a lower $V_{T}$ than that achieved with resuscitators that have flow-inflating bags. ${ }^{(12,14,15)}$ Even after receiving explicit instructions, the RTs produced $\mathrm{V}_{\mathrm{T}}$ values that were lower than those reported in other 
studies. ${ }^{(12,13,15,17)}$ That difference might be related solely to the size of the bag employed: $1.5 \mathrm{~L}$ in the present study, compared with 1.6-2.0 liters in the other studies cited. Much more favorable $\mathrm{PIF} / \mathrm{PEF}$ ratios have been reported when flowinflating devices were used. ${ }^{(13)}$

The verbal instruction on how to perform the $\mathrm{MH}$ improved the performance of the RTs in that the post-instruction maneuvers generated lower PIFs and longer $\mathrm{T}_{1}$ s. However, those differences did little to improve the efficiency of the technique, because the PEFs were still quite low. That is likely attributable to the fact that the $P_{\text {alv }}$ was also quite low at the start of exhalation, which resulted in a low driving pressure for expiratory flow. Other authors have reported great variability in the practical implementation of the MH maneuver, ${ }^{(4,5,13-15,26)}$ the execution of which rarely follows its original description. This makes it practically impossible to compare the effectiveness of MH across clinical studies. ${ }^{(27)}$

If we accept the concept that the relationship between PIF and PEF is responsible for the direction in which secretions move, ${ }^{(19-21)}$ we should question the use of an inspiratory pause on physiological grounds. Because of stress relaxation, the effective driving pressure for flow after a pause will be always lower than immediately after end-inspiration. ${ }^{(28)}$ Therefore the use of an inspiratory pause could decrease the PEF and, consequently, impair the efficiency of the $\mathrm{MH}$ maneuver.

The small number of RTs participating in this study prevents us from generalizing our data for application in clinical practice. However, we believe that this qualitative analysis, performed with representative operators (of both genders, recruited from different hospitals from within the same city), illustrated scenarios that commonly occur in some 1CUs. Another limitation of this study was the use of a lung model, which cannot be extrapolated to the complexity of human lungs. Nevertheless, we believe that similar results-high $\mathrm{PIF} / \mathrm{PEF}$ ratios, low $\mathrm{V}_{\mathrm{T}}$, and high $\mathrm{P}_{\text {prox }}$-would also be obtained in human patients on mechanical ventilation, especially in those that are heavily sedated, and this should draw the attention of the RTs to the way in which they perform the $\mathrm{MH}$ maneuver. Whether applying high PIF during $\mathrm{MH}$ will enhance secretion clearance in patients with preserved cough is a question that merits further investigation. That notwithstanding, the key message here is that performing $\mathrm{MH}$ with high PIF/PEF ratios in patients who are unable to cough will not aid secretion removal and might even contribute to mucus retention.

Another point that should be mentioned is that the MH maneuver can be performed in combination with expiratory chest compression in order to maximize the increase in the $\mathrm{PEF}^{(10,29)}$; however we were not able to investigate the use of that combination, because of the experimental system used. In addition, as previously mentioned, we cannot discard the possibility that the use of a different resuscitator device (a self-inflating resuscitator with larger internal volume bags or a flow-inflating resuscitator) might produce better results.

Given that, in Brazil, MH is typically performed without $\mathrm{P}_{\text {prox }}$ monitoring, the option of performing the maneuver with a mechanical ventilator, so that inspiratory flow, $\mathrm{V}_{\mathrm{T}}$ and pressure can be easily monitored and adjusted, ${ }^{(27,30)}$ should be considered. In studies comparing $\mathrm{MH}$ with a manual resuscitator and $\mathrm{MH}$ with a mechanical ventilator, ${ }^{(7,27,30)}$ no differences were found between the two modalities in terms of the amount of secretion removed, although the advantages of better monitoring with the mechanical ventilator were acknowledged.

It is important to note that, although the $\mathrm{MH}$ maneuver was originally designed to reduce lung collapse and to improve oxygenation or lung compliance, those potential benefits were not tested here. In fact, we believe that $\mathrm{MH}$ should be used only as a secretion clearance technique. If the technique is applied to recruit collapsed lungs, its beneficial effects are going to be offset, at least in part, by the fact that the patient must be disconnected from the ventilator, thus exposing the lung to the lower pressure of the ambient air at the end of each compression.

Finally, we found no evidence that the $\mathrm{MH}$ maneuver, as performed here, increases the risk of barotrauma. The $P_{\text {alv }}$ value is a result of the insufflating volume and lung compliance, $P_{\text {prox }}$ values that are higher than the $P_{\text {alv }}$ are caused by resistance in the orotracheal tube and airways. Although there have been anecdotal reports of high $\mathrm{P}_{\text {prox }}$ during $\mathrm{MH}$ in adults, with volumes $<1$ $\mathrm{L},{ }^{(17)}$ there is no hard evidence that the maneuver is dangerous.

In conclusion, when asked to apply $\mathrm{MH}$ in accordance with their routine clinical practice, 
this small sample of RTs performed the maneuver quite differently from what is recommended by experts, producing a concerning pattern of ventilation in terms of secretion clearance. The repetition of the maneuver after explicit instructions reduced the $\mathrm{P}_{\text {prox }}$ but did not help much. Alveolar pressures were usually low (because of the small generated $\mathrm{V}_{\mathrm{T}}$ ) despite high proximal pressures and high inspiratory peak flows. As a result, PEF was also low, far lower than the preceding PIF, a condition theoretically impacting the secretions deeper into the lung. Further studies are necessary in this area, especially focusing on the use of flow-inflating devices delivering higher tidal volumes.

\section{References}

1. Denehy L. The use of manual hyperinflation in airway clearance. Eur Respir J. 1999;14(4):958-65.

2. Paulus F, Binnekade JM, Vroom MB, Schultz MJ. Benefits and risks of manual hyperinflation in intubated and mechanically ventilated intensive care unit patients: a systematic review. Crit Care. 2012;16(4):R145.

3. Branson RD. Secretion management in the mechanically ventilated patient. Respir Care. 2007;52(10):1328-42; discussion 1342-7.

4. Paulus F, Binnekade JM, Middelhoek P, Schultz MJ, Vroom MB. Manual hyperinflation of intubated and mechanically ventilated patients in Dutch intensive care units--a survey into current practice and knowledge. Intensive Crit Care Nurs. 2009;25(4):199-207.

5. Paulus F, Binnekade JM, Middelhoek P, Vroom MB, Schultz MJ. Performance of manual hyperinflation: a skills lab study among trained intensive care unit nurses. Med Sci Monit. 2009;15(8):CR418-22.

6. Gosselink R, Bott J, Johnson M, Dean E, Nava S, Norrenberg $\mathrm{M}$, et al. Physiotherapy for adult patients with critical illness: recommendations of the European Respiratory Society and European Society of Intensive Care Medicine Task Force on Physiotherapy for Critically 111 Patients. Intensive Care Med. 2008;34(7):1188-99.

7. Dennis D, Jacob W, Budgeon C. Ventilator versus manual hyperinflation in clearing sputum in ventilated intensive care unit patients. Anaesth Intensive Care. 2012;40(1):142-9.

8. Nozawa E, Sarmento GJ, Vega JM, Costa D, Silva JE, Feltrim Ml. Perfil de fisioterapeutas brasileiros que atuam em unidades de terapia intensiva. Fisioter Pesqui. 2008;15(2):177-82.

9. França EE, Ferrari F, Fernandes P, Cavalcante R, Duarte A, Martinez BP, et al. Physical therapy in critically ill adult patients: recommendations from the Brazilian Association of Intensive Care Medicine Department of Physical Therapy. Rev Bras Ter Intensiva. 2012;24(1):6-22.

10. Berti JS, Tonon E, Ronchi CF, Berti HW, de Stefano LM, Gut AL, et al. Manual hyperinflation combined with expiratory rib cage compression for reduction of length of ICU stay in critically ill patients on mechanical ventilation. J Bras Pneumol. 2012;38(4):477-86.

11. Hodgson C, Denehy L, Ntoumenopoulos G, Santamaria J, Carroll S. An investigation of the early effects of manual lung hyperinflation in critically ill patients. Anaesth Intensive Care. 2000;28(3):255-61.

12. Maxwell L, Ellis ER. The effects of three manual hyperinflation techniques on pattern of ventilation in a test lung model. Anaesth Intensive Care. 2002;30(3):283-8.

13. Maxwell LJ, Ellis ER. Pattern of ventilation during manual hyperinflation performed by physiotherapists. Anaesthesia. 2007;62(1):27-33.

14. Maxwell LJ, Ellis ER. The effect of circuit type, volume delivered and "rapid release" on flow rates during manual hyperinflation. Aust J Physiother. 2003;49(1):31-8.

15. McCarren B, Chow CM. Manual hyperinflation: a description of the technique. Aust J Physiother. 1996;42(3):203-8.

16. Rusterholz B, Ellis E. The effect of lung compliance and experience on manual hyperinflation. Aust J Physiother. 1998;44(1):23-8.

17. Turki M, Young MP, Wagers SS, Bates JH. Peak pressures during manual ventilation. Respir Care. 2005;50(3):340-4.

18. Stiller K. Physiotherapy in intensive care: towards an evidence-based practice. Chest. 2000;118(6):1801-13.

19. Kim CS, Iglesias AJ, Sackner MA. Mucus clearance by two-phase gas-liquid flow mechanism: asymmetric periodic flow model. J Appl Physiol. 1987;62(3):959-71.

20. Benjamin RG, Chapman GA, Kim CS, Sackner MA. Removal of bronchial secretions by two-phase gas-liquid transport. Chest. 1989;95(3):658-63.

21. Volpe MS, Adams AB, Amato MB, Marini JJ. Ventilation patterns influence airway secretion movement. Respir Care. 2008;53(10):1287-94.

22. Clement AJ, Hübsch SK. Chest physiotherapy by the "bag squeezing' method: a guide to technique. Physiotherapy. 1968;54(10):355-9.

23. Singer M, Vermaat J, Hall G, Latter G, Patel M. Hemodynamic effects of manual hyperinflation in critically ill mechanically ventilated patients. Chest. 1994;106(4):1182-7.

24. Berney S, Denehy L, Pretto J. Head-down tilt and manual hyperinflation enhance sputum clearance in patients who are intubated and ventilated. Aust J Physiother. 2004;50(1):9-14.

25. Rodrigues MV. Estudo do comportamento hemodinâmico, da troca gasosa, da mecânica respiratória e da análise do muco brônquico na aplicação de técnicas de remoção de secreção brônquica em pacientes sob ventilação mecânica [thesis]. São Paulo: Universidade de São Paulo; 2007.

26. Patman S, Jenkins S, Smith K. Manual hyperinflation: consistency and modification of the technique by physiotherapists. Physiother Res Int. 2001;6(2):106-17.

27. Berney S, Denehy L. A comparison of the effects of manual and ventilator hyperinflation on static lung compliance and sputum production in intubated and ventilated intensive care patients. Physiother Res Int. 2002;7(2):100-8.

28. D’Angelo E, Milic-Emili J, Marazzini L. Effects of bronchomotor tone and gas density on time dependence of forced expiratory vital capacity maneuver. Am J Respir Crit Care Med. 1996;154(5):1318-22.

29. Dias CM, Siqueira TM, Faccio TR, Gontijo LC, Salge JA, Volpe MS. Bronchial hygiene technique with manual hyperinflation and thoracic compression: effectiveness and safety. Rev Bras Ter Intensiva. 2011;23(2):190-8.

30. Savian C, Paratz J, Davies A. Comparison of the effectiveness of manual and ventilator hyperinflation at different levels of positive end-expiratory pressure in artificially ventilated and intubated intensive care patients. Heart Lung. 2006;35(5):334-41. 


\section{About the authors}

Tatiana de Arruda Ortiz,

Adjunct Professor. Department of Physiotherapy. University of Cuiabá, Tangará da Serra, Brazil.

\section{Germano Forti}

Researcher. Laboratório de Investigação Médica 09 (LIM-09, Laboratory for Medical Research 09), specializing in Pulmonology, University of São Paulo School of Medicine, São Paulo, Brazil.

\section{Márcia Souza Volpe}

Adjunct Professor. Department of Physiotherapy. Federal University of Triângulo Mineiro, Uberaba, Brazil.

\section{Carlos Roberto Ribeiro Carvalho}

Full Professor of Pulmonology. University of São Paulo School of Medicine, São Paulo, Brazil.

Marcelo Brito Passos Amato

Coordinating Physician. Respiratory Intensive Care Unit, University of São Paulo School of Medicine Hospital das Clínicas, São Paulo, Brazil.

\section{Mauro Roberto Tucci}

Physician. Respiratory Intensive Care Unit, University of São Paulo School of Medicine Hospital das Clínicas, São Paulo, Brazil 